American Journal of Applied Sciences 8 (10): 1032-1040, 2011

ISSN 1546-9239

(C) 2011 Science Publications

\title{
Sliding Mode Observer-Based Fault Reconstruction for Uncertain Linear Systems
}

\author{
Slim Dhahri, Faycal Ben Hmida and Anis Sellami \\ Department of Electrical Engineering, \\ Higher School of Sciences and Techniques of Tunis, \\ University of Tunis, 5 Street Taha Hussein, B.P. 56-1008 Tunis, Tunisia
}

\begin{abstract}
Problem statement: Fault reconstruction scheme is different from the majority of Fault Detection and Isolation (FDI) methods described in the literature in the sense that it not only detects and isolates the fault, but provides an estimate of the fault. This approach is very useful for incipient faults and slow drifts, which are very difficult to detect. Also, this approach is very useful for Fault Tolerant Control (FTC) systems in the sense that instead of reconfiguration of the control system, the faulty sensors or actuators can be corrected and the simple control method can still be effectively used. Motivated by these useful features of fault, we are interested in performing observer-based fault reconstruction scheme for uncertain linear systems. Approach: In this study we present a scheme to design robust sliding mode observer for linear systems where both faults and uncertainties are considered. The objective is to derive a sufficient condition using Linear Matrix Inequalities (LMIs) for the stability of the observer. The so-called equivalent output error injection is discussed for fault reconstruction. Results: we get a simple sliding mode observer design for detection and reconstruction of faults for uncertain linear systems. Conclusion: With the real model of the seventh-order aircraft we show that the methods provided by present paper have good performances.
\end{abstract}

Key words: Sliding Mode Observer (SMO), Linear Matrix Inequalities (LMIs), fault reconstruction, Fault Detection and Isolation (FDI)

\section{INTRODUCTION}

Fault Detection and Isolation (FDI) has received considerable attention during the last three decades, both in research and in application. A fault is defined as an abnormal condition in a system with component malfunction or variation in operating condition. Fault in a dynamics system may occur in all possible location, such as actuators, sensors and system's parameters. The main function of an FDI scheme is to generate an alarm when a fault occurs (Fault Detection) and then to determine the location of the fault (fault isolation). There is a large variety of FDI approaches (Patton and Frank, 2000; Chen and Patton, 1999; Gertler, 1998; Prasannamoorthy and Devarajan, 2011; Chatchanayuenyong, 2009). The most effective methods for model based FDI are based on observers where the measured plant output is compared to the output of an observer and the output error are used to form a residual (Patton and Frank, 2000; Chen and Patton, 1999). The residual is then examined for the likelihood of faults by using a fixed or adaptive threshold.
Another approach different to residual generation is fault estimation or fault reconstruction which can determine the size, location and dynamics behavior of the fault. However, most fault reconstruction schemes are designed about a model, which usually possess uncertainties. These uncertainties could corrupt the reconstruction and could produce a false alarm. In this context, the robustness problem in fault reconstruction is essential.

Edwards et al. (2000) and Chamsai et al. (2010) proposed an approach based the equivalent output error injection where the sliding mode was maintained even in the presence of faults which can be reconstructed under certain conditions. Later it was extended by Tan and Edwards (2002) where sensor faults were considered. However, uncertainty was not considered in these early papers. A FDI scheme for a class of linear systems with uncertainty was proposed by Tan and Edwards (2003) who focused on minimizing the $\mathrm{L}_{2}$ gain between the uncertainty and the fault reconstruction signal using Linear Matrix Inequalities (LMIs).

Corresponding Author: Slim Dhahri, Department of Electrical Engineering, Higher School of Sciences and Techniques of Tunis, University of Tunis, 5 Street Taha Hussein, B.P. 56-1008 Tunis, Tunisia 
In this study, we develop a robust sliding mode observer design method for a class of uncertain linear systems which completely eliminate the effect of uncertainty on state estimation and fault reconstruction. A LMIs based sufficient condition is presented for the existence and stability of this observer. The design method will applied to reconstruct actuator faults using the equivalent output error injection concept.

\section{Notation:}

$\mathbb{R}^{\mathrm{n}}$ : Denotes the $\mathrm{n}$-dimensional real Euclidean space. For a square matrix

$\lambda_{\min }(\mathrm{A})$ : Denotes the minimum eigenvalue of $\mathrm{A}$

$\mathrm{I}_{\mathrm{n}}$ : $\quad$ Represents an $\mathrm{n}^{\text {th }}$ order identity matrix

$\mathbb{R}_{+}$: $\quad$ Represents the set of nonnegative real numbers

$\|$.$\| : Denotes the Euclidean norm or its induced$ norm

Problem formulation: Consider an uncertain dynamical system described by Eq. 1:

$\left\{\begin{array}{l}\dot{x}=A x+B u+E d(x, u, t)+D f_{a}(t) \\ y=C x\end{array}\right.$

where, $x \in \mathbb{R}^{\mathrm{n}}, \mathrm{y} \in \mathbb{R}^{\mathrm{p}}$ and $\mathrm{u} \in \mathbb{R}^{\mathrm{m}}$ are the state vector, output vector and input vector (the outputs of actuators) respectively. $\quad \mathrm{A} \in \mathbb{R}^{\mathrm{n} \times \mathrm{n}}, \mathrm{B} \in \mathbb{R}^{\mathrm{n} \times \mathrm{m}}, \mathrm{E} \in \mathbb{R}^{\mathrm{n \times r}}, \mathrm{D} \in \mathbb{R}^{\mathrm{n \times q}}$ and $C \in \mathbb{R}^{\mathrm{p} \times \mathrm{n}}(\mathrm{n}>\mathrm{p} \geq \mathrm{q})$ are all constant matrices with $\mathrm{D}$ and $\mathrm{C}$ both full rank and $(\mathrm{A}, \mathrm{C})$ is detectable. The signal $\quad d(x, u, t): \mathbb{R}^{n} \times \mathbb{R}^{m} \times \mathbb{R}^{+} \rightarrow \mathbb{R}^{r} \quad$ models the uncertainties and disturbances. The function $\mathrm{f}_{\mathrm{a}}(\mathrm{t}): \mathbb{R}^{+} \rightarrow \mathbb{R}^{q}$ denotes the fault (unknown input) that is bounded. made:

For the FDI design, the following assumptions are

Assumption 1: For $\mathrm{d}(\mathrm{x}, \mathrm{u}, \mathrm{t})$, there exists a positive constant $\mathrm{d}_{0}$ such that Eq. 2:

$\|\mathrm{d}(\mathrm{x}, \mathrm{u}, \mathrm{t})\| \leq \mathrm{d}_{0}$

Assumption 2: There is a positive constant $\rho$ such that the actuator fault $\mathrm{f}_{\mathrm{a}}(\mathrm{t})$ satisfies Eq. 3 :

$\left\|f_{a}(t)\right\| \leq \rho$

Assumption 3: Observer matching condition Eq. 4:

$\operatorname{rank}(\mathrm{CR})=\operatorname{rank}(\mathrm{R})=\mathrm{k}$ here we denote $\mathrm{R}=\left[\begin{array}{ll}\mathrm{E} & \mathrm{D}\end{array}\right]$

Assumption 4: Minimum Phase Condition: All invariant zeros of the system $(A, R, C)$ lie in the left half plane, that is Eq. 5:

$\operatorname{rank}\left[\begin{array}{cc}\mathrm{SI}-\mathrm{A} & \mathrm{R} \\ \mathrm{C} & 0\end{array}\right]=\mathrm{n}+\mathrm{k}$

for all complex number s with nonnegative real part.

As described in Yan and Edwards (2007), under Assumptions 3-4, there exists a non singular linear transformation $\quad\left[\begin{array}{ll}\mathrm{x}_{1}^{\mathrm{T}} & \mathrm{x}_{2}^{\mathrm{T}}\end{array}\right]^{\mathrm{T}}=\mathrm{T} \mathrm{x}$ with $\mathrm{x}_{1} \in \mathbb{R}^{\mathrm{n}-\mathrm{p}}$ and $\mathrm{x}_{2} \in \mathbb{R}^{\mathrm{p}}$ such that the matrices (A,E,D,C) from (1) in the new coordinates are given by Eq. 6 :

$A=\left[\begin{array}{ll}A_{1} & A_{2} \\ A_{3} & A_{4}\end{array}\right], E=\left[\begin{array}{c}0_{(n-p) \times r} \\ E_{2}\end{array}\right], D=\left[\begin{array}{c}0_{(n-p) \times q} \\ D_{2}\end{array}\right]$

$\mathrm{C}=\left[\begin{array}{ll}\left.0_{\mathrm{px}(\mathrm{n}-\mathrm{p}}\right) & \mathrm{C}_{2}\end{array}\right]$

where, $A_{1} \in \mathbb{R}^{(n-p) \times(n-p)}, C_{2} \in \mathbb{R}^{p \times p}$ is invertible. The subblocks $A_{1}, A_{3}, E_{2}, D_{2}$ when partitioned have the following structure Eq. 7:

$A_{1}=\left[\begin{array}{cc}A_{11} & A_{12} \\ 0_{(n-p-l) \times l} & A_{22}\end{array}\right], A_{3}=\left[\begin{array}{ll}\frac{0_{(p-k) x l}}{A_{32}} & A_{32}\end{array}\right]$
$E_{2}=\left[\begin{array}{c}0_{(p-k) \times r} \\ E_{22}\end{array}\right], D_{2}=\left[\begin{array}{c}0_{(p-k) \times q} \\ D_{22}\end{array}\right]$

where, $A_{11} \in \mathbb{R}^{1 \times 1}$ and $A_{31} \in \mathbb{R}^{(p-k) \times(n-p-1)}$ for some integer $1 \geq 0, E_{22} \in R^{k \times r}$ and the matrix $D_{22} \in R^{k \times q}$ is of full rank. By construction, the pair $\left(\mathrm{A}_{22}, \mathrm{~A}_{31}\right)$ is completely observable and the eigenvalues of $\mathrm{A}_{11}$ are the invariant zeros of the triple $(\mathrm{A}, \mathrm{R}, \mathrm{C})$ (Edwards and Spurgeon, 1998).

A sliding mode observer for the system (1) is Eq. 8:

$\left\{\begin{array}{l}\dot{\hat{x}}=A \hat{x}+B u-G_{1}(y-\hat{y})+G_{n} v \\ \hat{y}=C \hat{x}\end{array}\right.$

where $\hat{x} \in \mathbb{R}^{n}$ is the estimated of the state $x, \hat{y} \in \mathbb{R}^{p}$ is the estimated of the output $y$. The matrices $G_{1}$ $\mathrm{G}_{\mathrm{n}} \in \mathbb{R}^{\mathrm{n} \times \mathrm{p}}$ are observer gains that are to be designed. In particular, $\mathrm{G}_{\mathrm{n}}$ has the structure Eq. 9:

$$
\mathrm{G}_{\mathrm{n}}=\left[\begin{array}{c}
-\mathrm{L} \\
1_{\mathrm{p}}
\end{array}\right] \mathrm{C}_{2}^{-1}, \mathrm{~L}=\left[\begin{array}{ll}
\mathrm{L}_{1} & 0_{(\mathrm{n}-\mathrm{p}) \times \mathrm{k}}
\end{array}\right]
$$


Am. J. Applied Sci., 8 (10): 1032-1040, 2011

Where:

$\mathrm{L}_{1} \in \mathbb{R}^{(\mathrm{n}-\mathrm{p})(\mathrm{p}-\mathrm{k})}=$ Chosen such that $\mathrm{A}_{1}+\mathrm{L}_{1} \mathrm{~A}_{31}$.

$v \quad=\mathrm{A}$ nonlinear discontinuous injection term defined by Eq. 10:

$v:=\left\{\begin{array}{cl}\eta(y, u, t) \frac{P_{2}(y-\hat{y})}{\left\|P_{2}(y-\hat{y})\right\|} & \text { if } \quad y-\hat{y} \neq 0 \\ 0 & \text { otherwise }\end{array}\right.$

where, $\mathrm{P}_{2} \in \mathbb{R}^{\mathrm{p} \times \mathrm{p}}$ is a symmetric positive definite matrix which will be formally defined later. The scalar function $\eta(\mathrm{y}, \mathrm{u}, \mathrm{t})$ must be upper bound on the magnitude of the uncertainty plus the fault and satisfies Eq. 11:

$\eta(y, u, t) \geq\left\|C_{2} E_{2}\right\| d_{0}+\left\|C_{2} D_{2}\right\| \rho+\eta_{0}$

where $\eta_{0}>0$ is a small positive scalar.

Subtracting observer Eq. 8 from system Eq. 1 results in the system error dynamics Eq 12:

$$
\left\{\begin{array}{l}
\dot{e}=\left(A-G_{1} C\right) e+E d(x, u, t)+D f_{a}(t) \\
e_{y}=C e
\end{array}\right.
$$

where $\mathrm{e}:=\mathrm{x}-\hat{\mathrm{x}}$ is the state estimate error and $e_{y}:=y-\hat{y}$ is the output estimation error.

Firstly, two lemmas will be introduced to provide the stability of sliding motion.

For system (12), consider the sliding surface Eq. 13:

$$
\mathcal{S}=\left\{\mathrm{e} \mid \mathrm{e}_{\mathrm{y}}=\mathrm{Ce}=0\right\}
$$

Lemma 1: If an ideal sliding motion takes place on $S$ in finite time, then the sliding dynamics are given by the system matrix $A_{1}+L_{1} A_{31}$.

Proof: Assume that an ideal sliding mode exists then the error system (12) will become Eq. 14:

$$
0=C\left(A-G_{1} C\right) e+C E d(x, u, t)+C D f_{a}(t)-C_{n} v
$$

In order for a unique equivalent output injection to existe $\operatorname{det}\left(\mathrm{CG}_{\mathrm{n}}\right) \neq 0$, it follows from (14) that Eq. 15:

$$
\dot{\mathrm{e}}=\left(1-\mathrm{G}_{\mathrm{n}}\left(\mathrm{CG}_{\mathrm{n}}^{-1} \mathrm{C}\right)\left(\left(\mathrm{A}-\mathrm{G}_{1} \mathrm{C}\right) \mathrm{e}+\mathrm{Ed}(\mathrm{x}, \mathrm{u}, \mathrm{t})+\mathrm{Df}_{\mathrm{a}}(\mathrm{t})\right.\right.
$$

A sliding motion insensitive to the faults and uncertainties is governed then by Eq. 16:
$\left(1-G_{n}\left(C G_{n}^{-1} C\right)\left(A-G_{1} C\right) e=\left[\begin{array}{cc}A_{1}+L_{3} & A_{2}+A_{4} \\ 0 & 0\end{array}\right]\right.$

Hence the reduced order sliding motion is governed by $A_{1}+L_{1} A_{31}$.

Lemma 2: under assumption 4, there exists a matrix $\mathrm{L} \in \mathbb{R}^{(\mathrm{n}-\mathrm{p}) \times \mathrm{p}}$ from structure (9) such that the matrix $\mathrm{A}_{1}+$ $\mathrm{LA}_{3}$ is stable.

Proof: Using the fact that $\left(\mathrm{A}_{22}, \mathrm{~A}_{31}\right)$ is observable if follows that there exists a matrix $\mathrm{L}_{12} \in \mathrm{R}^{(\mathrm{n}-\mathrm{p}-\mathrm{l}) \times(\mathrm{p}-\mathrm{k})}$ such that $A_{22}+L_{12} A_{31}$ is stable. Partition L from (9) as Eq. 17:

$\mathrm{L}=\left[\begin{array}{cc}\mathrm{L}_{11} & 0_{1 \times k} \\ \mathrm{~L}_{12} & 0_{(\mathrm{n}-\mathrm{p}-1) \times \mathrm{k}}\end{array}\right]$

Then, from the partition in (7), it follows that Eq. 18:

$A_{1}+L_{3}=\left[\begin{array}{cc}A_{11} & A_{12}+L_{11} A_{31} \\ 0 & A_{22}+L_{12} A_{31}\end{array}\right]$

Therefore $A_{1}+L_{3}$ is stable from the stability of $\mathrm{A}_{11}$ and $\mathrm{A}_{22}+\mathrm{L}_{12} \mathrm{~A}_{31}$.

Reduced-order Sliding mode observer design: One way to identify the reduced order sliding motion is to perform a further change of coordinates according to the nonsingular matrix Eq. 19:

$\mathrm{T}_{\mathrm{L}}=\left[\begin{array}{cc}\mathrm{I}_{\mathrm{n}-\mathrm{p}} & \mathrm{L} \\ 0 & \mathrm{C}_{2}\end{array}\right]$

Hence, the matrices (A, E, D, C) from (6) and $G_{n}$ from (9) are transformed to be Eq. 20:

$\mathcal{A}=\left[\begin{array}{ll}\mathcal{A}_{1} & \mathcal{A}_{2} \\ \mathcal{A}_{3} & \mathcal{A}_{4}\end{array}\right], \mathcal{E}=\left[\begin{array}{c}0 \\ \mathcal{E}_{2}\end{array}\right], \mathcal{D}=\left[\begin{array}{c}0 \\ \mathcal{D}_{2}\end{array}\right], \mathcal{C}=\left[\begin{array}{ll}0 & \mathrm{I}_{\mathrm{p}}\end{array}\right]$
$\mathcal{G}_{\mathrm{n}}=\left[\begin{array}{c}0 \\ \mathrm{I}_{\mathrm{p}}\end{array}\right]$

where $\mathcal{A}_{1}=\mathrm{A}_{1}+\mathrm{LA}_{3}, \mathcal{A}_{3}=\mathrm{C}_{2} \mathrm{~A}_{3}, \mathcal{D}_{2}=\mathrm{C}_{2} \mathrm{D}_{2}$ and $\mathcal{E}_{2}=\mathrm{C}_{2} \mathrm{E}_{2}$ Define Eq. 21:

$\mathrm{T}_{\mathrm{L}} \mathrm{e}=:\left[\begin{array}{l}\mathrm{e}_{1} \\ \mathrm{e}_{\mathrm{y}}\end{array}\right], \mathrm{T}_{\mathrm{L}} \mathrm{G}_{1}=:\left[\begin{array}{c}\mathcal{G}_{1,1} \\ \mathcal{G}_{1,2}\end{array}\right]$

and choose $\mathcal{G}_{1}$ so that $\mathcal{G}_{1,1}=\mathcal{A}_{2}, \mathcal{G}_{1,2}=\mathcal{A}_{4}+\mathcal{A}_{\mathrm{s}}$ where $\mathcal{A}_{\mathrm{s}}$ is a stable design matrix. For simplicity in the subsequent 
analysis, it will be assumed that $\mathcal{A}_{\mathrm{s}}$ is symmetric negative definite. This is not a stringent assumption since $\mathcal{A}_{\mathrm{s}}$ is a design parameter.

Partitioning the state estimation error (12) conformably with (20) yields Eq. 22:

$$
\left\{\begin{array}{l}
\dot{\mathrm{e}}_{1}=\mathcal{A}_{1} \mathrm{e}_{1} \\
\dot{\mathrm{e}}_{\mathrm{y}}=\mathcal{A}_{\mathrm{s}} \mathrm{e}_{\mathrm{y}}+\mathcal{A}_{3} \mathrm{e}_{1}+\mathcal{E}_{2} \mathrm{~d}(\mathrm{x}, \mathrm{u}, \mathrm{t})+\mathcal{D}_{2} \mathrm{f}_{\mathrm{a}}(\mathrm{t})-v
\end{array}\right.
$$

\section{MATERIALS AND METHODS}

To show the stability of sliding motion we analyze the dynamic performance of error system (22) using Lyapunov method and derive a sufficient condition for the asymptotically stability of the sliding dynamics via Linear Matrix Inequalities techniques.

\section{RESULTS AND DISCUSSION}

Theorem 1: Under Assumptions 1-4, the sliding motion of system (22) associated with the sliding surface (13) is asymptotically stable if there exist symmetric positive matrices $\mathrm{P}_{1} \in \mathbb{R}^{(\mathrm{n}-\mathrm{p}) \times(\mathrm{n}-\mathrm{p})}$, $\mathrm{P}_{2} \in \mathbb{R}^{\mathrm{p} \times \mathrm{p}}$ and a matrix $\mathrm{Y} \in \mathbb{R}^{\mathrm{n} \times \mathrm{p}}$ such that the following LMI condition is satisfied Eq. 23 and 24:

$$
\left[\begin{array}{cc}
\mathrm{P}_{1} \mathrm{~A}_{1}+\mathrm{A}_{1}^{\mathrm{T}} \mathrm{P}_{1}+\mathrm{YA}_{3}+\mathrm{A}_{3}^{\mathrm{T}} \mathrm{Y}^{\mathrm{T}} & \left(\mathrm{P}_{2} \mathrm{C}_{2} \mathrm{~A}_{3}\right)^{\mathrm{T}} \\
\mathrm{P}_{2} \mathrm{C}_{2} \mathrm{~A}_{3} & \mathrm{P}_{2} \mathcal{A}_{\mathrm{s}}+\mathcal{A}_{\mathrm{s}}^{\mathrm{T}} \mathrm{P}_{2}
\end{array}\right]<0
$$

Where:

$\mathrm{L}=\mathrm{P}_{1}^{-1} \mathrm{Y}$

Proof: Rewriting Eq. 22 in terms of the coordinates in (6) yields Eq. 25 and 26:

$$
\begin{aligned}
& \dot{\mathrm{e}}_{1}=\left(\mathrm{A}_{1}+\mathrm{LA}_{3}\right) \mathrm{e}_{1} \\
& \dot{\mathrm{e}}_{\mathrm{y}}=\mathcal{A}_{\mathrm{s}} \mathrm{e}_{\mathrm{y}}+\mathrm{C}_{2} \mathrm{~A}_{3} \mathrm{e}_{1}+\mathrm{C}_{2} \mathrm{E}_{2} \mathrm{~d}(\mathrm{x}, \mathrm{u}, \mathrm{t})+\mathrm{C}_{2} \mathrm{D}_{2} \mathrm{f}_{\mathrm{a}}(\mathrm{t})-\mathrm{v}
\end{aligned}
$$

Consider the following Lyapunov function candidate Eq. 27:

$$
\begin{aligned}
V\left(e_{1}, e_{y}\right) & =\left[\begin{array}{l}
e_{1} \\
e_{y}
\end{array}\right]^{T}\left[\begin{array}{cc}
P_{1} & 0 \\
0 & P_{2}
\end{array}\right]\left[\begin{array}{l}
e_{1} \\
e_{y}
\end{array}\right] \\
& =e_{1}^{T} P_{1} e_{1}+e_{y}^{T} P_{2} e_{y}
\end{aligned}
$$

where, $\quad \mathrm{P}_{1} \in \mathbb{R}^{(\mathrm{n}-\mathrm{p}) \times(\mathrm{n}-\mathrm{p})}$ and $\mathrm{P}_{2} \in \mathbb{R}^{\mathrm{p} \times \mathrm{p}}$ are symmetric positive definite matrices. Then, the time derivative of
(27) along the trajectory of the error system (25)-(26) can be calculated as follows Eq. 28:

$$
\begin{aligned}
\dot{\mathrm{V}}= & \mathrm{e}_{1}^{\mathrm{T}}\left(\mathrm{P}_{1}\left(\mathrm{~A}_{1}+\mathrm{LA}_{3}\right)+\left(\mathrm{A}_{1}+\mathrm{LA}_{3}\right)^{\mathrm{T}} \mathrm{P}_{1}\right) \mathrm{e}_{1} \\
& +\mathrm{e}_{\mathrm{y}}^{\mathrm{T}}\left(\mathrm{P}_{2} \mathcal{A}_{\mathrm{s}}+\mathcal{A}_{\mathrm{s}}^{\mathrm{T}} \mathrm{P}_{2}\right) \mathrm{e}_{\mathrm{y}}+2 \mathrm{e}_{\mathrm{y}}^{\mathrm{T}} \mathrm{P}_{2} \mathrm{C}_{2} \mathrm{~A}_{3} \mathrm{e}_{1}+2 \mathrm{e}_{\mathrm{y}}^{\mathrm{T}} \mathrm{P}_{2} \mathrm{C}_{2} \mathrm{E}_{2} \mathrm{~d} \\
& +2 \mathrm{e}_{\mathrm{y}}^{\mathrm{T}} \mathrm{P}_{2} \mathrm{C}_{2} \mathrm{D}_{2} \mathrm{f}_{\mathrm{a}}
\end{aligned}
$$

Considering inequality (11) and substituting the $v$ given in (10) into (28), we have Eq. 29:

$$
\begin{aligned}
& 2 \mathrm{e}_{\mathrm{y}}^{\mathrm{T}} \mathrm{P}_{2} \mathrm{C}_{2} \mathrm{E}_{2} \mathrm{~d}+2 \mathrm{e}_{\mathrm{y}}^{\mathrm{T}} \mathrm{P}_{2} \mathrm{C}_{2} \mathrm{D}_{2} \mathrm{f}_{\mathrm{a}}-2 \mathrm{e}_{\mathrm{y}}^{\mathrm{T}} \mathrm{P}_{2} \mathrm{v} \\
& \leq 2\left\|\mathrm{P}_{2} \mathrm{e}_{\mathrm{y}}\right\|\left(\left\|\mathrm{C}_{2} \mathrm{E}_{2}\right\|\|\mathrm{d}\|+\left\|\mathrm{C}_{2} \mathrm{D}_{2}\right\|\left\|\mathrm{f}_{\mathrm{a}}\right\|\right)-2 \eta(.)\left(\mathrm{P}_{2} \mathrm{e}_{\mathrm{y}}\right)^{\mathrm{T}} \frac{\mathrm{P}_{2} \mathrm{e}_{\mathrm{y}}}{\left\|\mathrm{P}_{2} \mathrm{e}_{\mathrm{y}}\right\|} \\
& \leq 2\left\|\mathrm{P}_{2} \mathrm{e}_{\mathrm{y}}\right\|\left(\left\|\mathrm{C}_{2} \mathrm{E}_{2}\right\| \mathrm{d}_{0}+\left\|\mathrm{C}_{2} \mathrm{D}_{2}\right\| \rho-\eta(.)\right) \leq-2 \gamma 0\left\|\mathrm{P}_{2} \mathrm{e}_{\mathrm{y}}\right\|
\end{aligned}
$$

Combining Eq. 29 into Eq. 28 yields:

$$
\begin{aligned}
\dot{\mathrm{V}} \leq & \mathrm{e}_{1}^{\mathrm{T}}\left(\mathrm{P}_{1}\left(\mathrm{~A}_{1}+\mathrm{LA}_{3}\right)+\left(\mathrm{A}_{1}+\mathrm{LA}_{3}\right)^{\mathrm{T}} \mathrm{P}_{1}\right) \mathrm{e}_{1} \\
& +\mathrm{e}_{\mathrm{y}}^{\mathrm{T}}\left(\mathrm{P}_{2} \mathcal{A}_{\mathrm{s}}+\mathcal{A}_{\mathrm{s}}^{\mathrm{T}} \mathrm{P}_{2}\right) \mathrm{e}_{\mathrm{y}}+2 \mathrm{e}_{\mathrm{y}}^{\mathrm{T}} \mathrm{P}_{2} \mathrm{C}_{2} \mathrm{~A}_{3} \mathrm{e}_{1}-2 \gamma 0\left\|\mathrm{P}_{2} \mathrm{e}_{\mathrm{y}}\right\|
\end{aligned}
$$

If the condition (11) is satisfied, then Eq. 30 can be written as Eq. 31 and 32:

$$
\dot{\mathrm{V}} \leq\left[\begin{array}{l}
\mathrm{e}_{1} \\
\mathrm{e}_{\mathrm{y}}
\end{array}\right]^{\mathrm{T}} \Omega\left[\begin{array}{l}
\mathrm{e}_{1} \\
\mathrm{e}_{\mathrm{y}}
\end{array}\right]-2 \gamma 0\left\|\mathrm{P}_{2} \mathrm{e}_{\mathrm{y}}\right\|
$$

Where:

$$
\Omega=\left[\begin{array}{cc}
\mathrm{P}_{1}\left(\mathrm{~A}_{1}+\mathrm{LA}_{3}\right)+\left(\mathrm{A}_{1}+\mathrm{LA}_{3}\right)^{\mathrm{T}} \mathrm{P}_{1} & \left(\mathrm{P}_{2} \mathrm{C}_{2} \mathrm{~A}_{3}\right)^{\mathrm{T}} \\
\mathrm{P}_{2} \mathrm{C}_{2} \mathrm{~A}_{3} & \mathrm{P}_{2} \mathcal{A}_{\mathrm{s}}+\mathcal{A}_{\mathrm{s}}^{\mathrm{T}} \mathrm{P}_{2}
\end{array}\right]
$$

If $\Omega<0$ then $\dot{V}<0$. Thus, the observer error dynamics (22) is asymptotically stable. Notice that the Inequality (32) is not linear because of the product $\mathrm{P}_{1} \mathrm{~L}$. This problem can be solved by using the changes of variables $\mathrm{Y}=\mathrm{P}_{1} \mathrm{~L}$. Therefore, Inequality (23) can then be obtained.

Remark 1: Note that the problem of finding symmetric positive matrices $\mathrm{P}_{1}, \mathrm{P}_{2}$ and a matrix $\mathrm{Y}$ to satisfy (23) is a standard LMI feasibility problem which can be solved using the standard LMI algorithm (Gahinet et al., 1995).

Reachability of the sliding motion: In order to ensure the stability of the observer it is only required to prove that the error system (22) can be driven to the sliding surface $\mathcal{S}$ in finite time by choosing an appropriate gain $\eta(y, u, t)$ in $(12)$. 
Theorem 2: Under Assumptions 1-4, the error system (22) is driven to the sliding surface $\mathcal{S}$ and remains on it if the gain $\eta(y, u, t)$ in (12) is chosen to satisfy Eq. 33:

$$
\eta(y, u, t) \geq\left\|C_{2} A_{3}\right\| \kappa+\left\|C_{2} E_{2}\right\| d_{0}+\left\|C_{2} D_{2}\right\| \rho+\eta_{1}
$$

where, $\eta_{1}$ is a positive scalar, $d_{0}$ and $\rho$ are the upper bounds of $d$ and $f_{a}$, respectively.

Proof: Consider the following Lyapunov function candidate Eq. 34:

$$
V\left(e_{y}\right)=e_{y}^{T} P_{2} e_{y}
$$

The derivative along the trajectory is given by Eq. 35:

$$
\begin{aligned}
\dot{\mathrm{V}}= & \mathrm{e}_{\mathrm{y}}^{\mathrm{T}}\left(\mathrm{P}_{2} \mathcal{A}_{\mathrm{s}}+\mathcal{A}_{\mathrm{s}}^{\mathrm{T}} \mathrm{P}_{2}\right) \mathrm{e}_{\mathrm{y}}+2 \mathrm{e}_{\mathrm{y}}^{\mathrm{T}} \mathrm{P}_{2} \mathrm{C}_{2} \mathrm{~A}_{3} \mathrm{e}_{1}+2 \mathrm{e}_{\mathrm{y}}^{\mathrm{T}} \mathrm{P}_{2} \mathrm{C}_{2} \mathrm{E}_{2} \mathrm{~d} \\
& +2 \mathrm{e}_{\mathrm{y}}^{\mathrm{T}} \mathrm{p}_{2} \mathrm{C}_{2} \mathrm{D}_{2} \mathrm{f}_{\mathrm{a}}-2 \mathrm{e}_{\mathrm{y}}^{\mathrm{T}} \mathrm{P}_{2} \mathrm{v}
\end{aligned}
$$

Using the fact that as $\mathcal{A}_{\mathrm{s}}$ is stable design matrix, it follows that Eq. 36:

$$
\mathrm{P}_{2} \mathcal{A}_{\mathrm{s}}+\mathcal{A}_{\mathrm{s}}^{\mathrm{T}} \mathrm{P}_{2}<0
$$

By applying (2), (3) and (33), we obtain Eq. 37:

$$
\begin{aligned}
& \dot{\mathrm{V}} \leq 2\left\|\mathrm{P}_{2} \mathrm{e}_{\mathrm{y}}\right\|\left(\left\|\mathrm{C}_{2} \mathrm{~A}_{3}\right\|\left\|\mathrm{e}_{1}\right\|+\left\|\mathrm{C}_{2} \mathrm{E}_{2}\right\|\|\mathrm{d}\|+2\left\|\mathrm{C}_{2} \mathrm{D}_{2}\right\|\left\|\mathrm{f}_{\mathrm{a}}\right\|\right) \\
& \quad-2 \eta(\mathrm{y}, \mathrm{u}, \mathrm{t})\left(\mathrm{P}_{2} \mathrm{e}_{\mathrm{y}}\right)^{\mathrm{T}} \frac{\mathrm{P}_{2} \mathrm{e}_{\mathrm{y}}}{\left\|\mathrm{P}_{2} \mathrm{e}_{\mathrm{y}}\right\|} \\
& \leq 2\left\|\mathrm{P}_{2} \mathrm{e}_{\mathrm{y}}\right\|\left(\left\|\mathrm{C}_{2} \mathrm{~A}_{3}\right\|\left\|\mathrm{e}_{1}\right\|+\left\|\mathrm{C}_{2} \mathrm{E}_{2}\right\| \mathrm{d}_{0}+\left\|\mathrm{C}_{2} \mathrm{D}_{2}\right\| \rho-\eta(\mathrm{y}, \mathrm{u}, \mathrm{t})\right)
\end{aligned}
$$

From Theorem 1 , the error $\mathrm{e}_{1}(\mathrm{t})$ is asymptotically stable. Thus, there exist an instant $t_{f}$ and a positive scalar k such That Eq. 38:

$$
\left\|\mathrm{e}_{1}(\mathrm{t})\right\| \leq \kappa, \forall \mathrm{t} \geq \mathrm{t}_{\mathrm{f}}
$$

Therefore from the definition of $\eta(y, u, t)$ in (33), it follows that $\forall \mathrm{t} \geq \mathrm{t}_{\mathrm{f}}$ :

$$
\begin{aligned}
\dot{\mathrm{V}} & \leq-2 \eta_{1}\left\|\mathrm{P}_{2} \mathrm{e}_{\mathrm{y}}\right\| \forall \mathrm{t} \geq \mathrm{t}_{\mathrm{f}} \\
& \leq-2 \eta_{1} \sqrt{\lambda_{\text {min }}\left(\mathrm{P}_{2}\right)} \sqrt{\mathrm{V}}
\end{aligned}
$$

Integrating the last deferential inequality, it follows that an ideal sliding motion is achieved and maintained after some finite time (Utkin, 1992).

Design of the sliding motion system matrix: This section considers the sliding motion design problem and shows how additional LMI constraints can be augmented to tune the sliding mode performance. One approach is to achieve pole placement of $\mathcal{A}_{1}=\mathrm{A}_{1}+\mathrm{LA}_{3}$ in regions of the complex plane.

Definition 1: Chilali and Gahinet (1996) a subset D of the complex plane $\mathbb{C}$ is called an LMI region if there exist a symmetric matrix $\mathrm{R} \in \mathbb{R}^{\mathrm{n} \times \mathrm{n}}$ and a matrix $\mathrm{S} \in \mathbb{R}^{\mathrm{n} \times \mathrm{n}}$ such that Eq. 40:

$\mathrm{D}=\left\{\mathrm{z} \in \mathbb{C} \mid \mathrm{f}_{\mathrm{D}}(\mathrm{z}):=\mathrm{R}+\mathrm{zS}+\overline{\mathrm{z}} \mathrm{S}^{\mathrm{T}}<0\right\}$

The matrix A is called D-stable if all its poles lie in A sub region of the complex left-half plane. As an example, the poles may be required to lie in the following sectors:

- $\quad$ Disk of radius $r$ and center $(q, 0)$

- Conic sector centred at $(0,0)$ with inner angle $\theta$

- Vertical strip $-\mathrm{h}_{1}<\mathrm{x}<-\mathrm{h}_{2}<0$

Chilali and Gahinet (1996) have proven that these sectors are an LMI region described by the following inequalities:

$$
\begin{aligned}
& {\left[\begin{array}{cc}
-\mathrm{P}_{1} & \mathrm{P}_{1} \mathcal{A}_{1}-\mathrm{q} \mathrm{P}_{1} \\
\mathcal{A}_{1}^{\mathrm{T}} \mathrm{P}_{1}-\mathrm{qP}_{1} & -\mathrm{r} \mathrm{P}_{1}
\end{array}\right]<0} \\
& {\left[\begin{array}{cc}
\left(\mathcal{A}_{1}^{\mathrm{T}} \mathrm{P}_{1}+\mathrm{P}_{1} \mathcal{A}_{1}\right) \sin \theta & \left(\mathcal{A}_{1}^{\mathrm{T}} \mathrm{P}_{1}-\mathrm{P}_{1} \mathcal{A}_{1}\right) \cos \theta \\
\left(\mathrm{P}_{1} \mathcal{A}_{1}-\mathcal{A}_{1}^{\mathrm{T}} \mathrm{P}_{1}\right) \cos \theta & \left(\mathcal{A}_{1}^{\mathrm{T}} \mathrm{P}_{1}+\mathrm{P}_{1} \mathcal{A}_{1}\right) \sin \theta
\end{array}\right]<0} \\
& \left\{\begin{array}{l}
\mathrm{P}_{1} \mathcal{A}_{1}+\mathcal{A}_{1}^{\mathrm{T}} \mathrm{P}_{1}+2 \mathrm{~h}_{2} \mathrm{P}_{1}<0 \\
-\left(\mathrm{P}_{1} \mathcal{A}_{1}+\mathcal{A}_{1}^{\mathrm{T}} \mathrm{P}_{1}\right)-2 \mathrm{~h}_{1} \mathrm{P}_{1}<0
\end{array}\right.
\end{aligned}
$$

Therefore, the dynamics of the sliding motion are designed by solved the LMIs (23) and (41)-(43).

Robust actuator fault reconstruction: From the Theorems 1 and 2, it follows that a sliding motion takes place in finite time and during the sliding motion Eq. 44:

$$
\mathrm{e}_{\mathrm{y}}(\mathrm{t})=0 \text { and } \dot{\mathrm{e}}_{\mathrm{y}}(\mathrm{t})=0
$$

Consequently, the error dynamics for $\mathrm{e}_{\mathrm{y}}$ in sliding mode is given by Eq. 45:

$\mathrm{C}_{2}^{-1} v_{\text {eq }}=\mathrm{A}_{3} \mathrm{e}_{1}+\mathrm{E}_{2} \mathrm{~d}(\mathrm{x}, \mathrm{u}, \mathrm{t})+\mathrm{D}_{2} \mathrm{f}_{\mathrm{a}}(\mathrm{t})$

where, $v_{\text {eq }}$ denotes the equivalent output error injection and represents the average behavior of the 
discontinuous function $v(t)$ defined by (10), which is necessary to maintain an ideal sliding motion

Applying the structural properties of $E_{2}$ and $D_{2}$ in (7), yields Eq. 46:

$$
\begin{aligned}
{\left[\begin{array}{ll}
0_{k \times(p-k)} & I_{k}
\end{array}\right] C_{2}^{-1} v_{e q} } & =\left[\begin{array}{ll}
0_{k \times(p-k)} & I_{k}
\end{array}\right] A_{3} e_{1} \\
& +\left[\begin{array}{ll}
E_{22} & D_{22}
\end{array}\right]\left[\begin{array}{c}
d(x, u, t) \\
f_{a}(t)
\end{array}\right]
\end{aligned}
$$

Suppose the case that the geometric condition $\operatorname{Im}(E) \cap \operatorname{Im}(D)=\{0\}$ holds. Then by using the nonsingular transformation $\mathrm{T}$ we have $\left.\operatorname{Im}(\mathrm{TE}) \cap \operatorname{Im}(\mathrm{TD})=\{0\} \Rightarrow \operatorname{Im}\left(\left[\begin{array}{c}0 \\ \mathrm{E}_{22}\end{array}\right]\right) \cap \operatorname{Im}\left(\begin{array}{c}0 \\ D_{22}\end{array}\right]\right)=\{0\} \quad$ it follows that $\operatorname{Im}\left(E_{22}\right) \cap \operatorname{Im}\left(D_{22}\right)=\{0\}$ then there exists a nonsingular matrix $\mathrm{W} \in \mathbb{R}^{\mathrm{k} \times \mathrm{k}}$ such that Eq. 47:

$$
\mathrm{W}\left[\mathrm{E}_{22} \quad \mathrm{D}_{22}\right]=\left[\begin{array}{cc}
\mathrm{H}_{1} & 0 \\
0 & \mathrm{H}_{2}
\end{array}\right]
$$

where, $\mathrm{H}_{1} \in \mathbb{R}^{(\mathrm{k}-\mathrm{q}) \times \mathrm{r}}$ and $\mathrm{H}_{2} \in \mathbb{R}^{\mathrm{q} \times \mathrm{q}}$ is nonsingular. This condition guarantees that the fault can be completely decoupled from uncertainty.

Multiplying both sides of (46) by Y yields Eq. 48:

$$
\begin{aligned}
\mathrm{W}\left[\begin{array}{ll}
0_{\mathrm{k} \times(\mathrm{p}-\mathrm{k})} & \mathrm{I}_{\mathrm{k}}
\end{array}\right] \mathrm{C}_{2}^{-1} v_{\text {eq }} & =\mathrm{W}\left[\begin{array}{ll}
0_{\mathrm{k} \times(\mathrm{p}-\mathrm{k})} & \mathrm{I}_{\mathrm{k}}
\end{array}\right] \mathrm{A}_{3} \mathrm{e}_{1} \\
+ & {\left[\begin{array}{cc}
\mathrm{H}_{1} & 0 \\
0 & \mathrm{H}_{2}
\end{array}\right]\left[\begin{array}{c}
\mathrm{d}(\mathrm{x}, \mathrm{u}, \mathrm{t}) \\
\mathrm{f}_{\mathrm{a}}(\mathrm{t})
\end{array}\right] }
\end{aligned}
$$

Let $\mathrm{W}_{2}$ denote the last $\mathrm{q}$ rows of $\mathrm{W}$. It follows from (48) that Eq. 49:

$$
\begin{aligned}
\mathrm{W}_{2}\left[\begin{array}{ll}
0_{\mathrm{k} \times(\mathrm{p}-\mathrm{k})} & \mathrm{I}_{\mathrm{k}}
\end{array}\right] \mathrm{C}_{2}^{-1} \mathrm{v}_{\mathrm{eq}} & =\mathrm{W}_{2}\left[\begin{array}{ll}
0_{\mathrm{k} \times(\mathrm{p}-\mathrm{k})} & \mathrm{I}_{\mathrm{k}}
\end{array}\right] \mathrm{A}_{3} \mathrm{e}_{1} \\
& +\mathrm{H}_{2} \mathrm{f}_{\mathrm{a}}(\mathrm{t})
\end{aligned}
$$

and since $\mathrm{H}_{2}$ is non singular, yields Eq. 50:

$$
\begin{aligned}
f_{a}(t)= & H_{2}^{-1} W_{2}\left[\begin{array}{ll}
0_{k \times(p-k)} & I_{k}
\end{array}\right] C_{2}^{-1} v_{e q} \\
& -H_{2}^{-1} W_{2}\left[\begin{array}{ll}
0_{k \times(p-k)} & I_{k}
\end{array}\right] A_{3} e_{1}
\end{aligned}
$$

Now, it is required to recover the equivalent output error injection $v_{\text {eq }}$. Two practical approaches can be used. The first approach is to pass the output of the injection term $v_{\text {eq }}$ through a low-pass filter. The second approach is to use a boundary layer to smooth out the discontinuous $v_{\text {eq }}$. Here the approach given in (Edwards and Spurgeon, 1998) will be employed to produce the $v_{\text {eq. }}$ From (10), the equivalent output error injection signal $v_{\text {eq }}$ can be approximated by Eq. 51:

$$
v_{\sigma}=\eta(y, u, t) \frac{P_{2} e_{y}}{\left\|P_{2} e_{y}\right\|+\sigma}
$$

where, $\sigma$ is a small positive scalar. Define a would-be actuator fault reconstruction:

$\hat{\mathrm{f}}_{\mathrm{a}}(\mathrm{t})=\mathrm{H}_{2}^{-1} \mathrm{~W}_{2}\left[0_{\mathrm{k} \times(\mathrm{p}-\mathrm{k})} \quad \mathrm{I}_{\mathrm{k}}\right] \mathrm{C}_{2}^{-1} \mathrm{v}_{\sigma}$

Then from (50) and (52) Eq. 53:

$$
\begin{aligned}
f_{a}(t)- & \hat{f}_{a}(t)=H_{2}^{-1} Y_{2}\left[\begin{array}{ll}
0_{k \times(p-k)} & I_{k}
\end{array}\right] C_{2}^{-1}\left(v_{e q}-v_{\sigma}\right) \\
- & H_{2}^{-1} Y_{2}\left[\begin{array}{ll}
0_{k \times(p-k)} & I_{k}
\end{array}\right] A_{3} e_{1}
\end{aligned}
$$

Since $\lim _{\mathrm{t} \rightarrow \infty} \mathrm{e}_{1}(\mathrm{t})=0$ and since $\left\|v_{\mathrm{eq}}-v_{\sigma}\right\|$ can be made arbitrarily small by choice of $\sigma$ then $\hat{f}_{a}(t)$ defined by (52) is a reconstruction for the actuator fault $f_{a}(t)$.

An illustrative example: The method proposed in this paper will now be demonstrated with an example, which is a seventh-order model of an aircraft (Yan and Edwards, 2007). The states are:

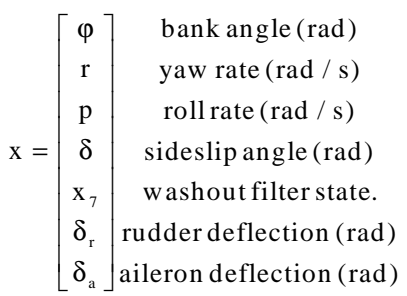

The inputs are:

$$
\mathrm{u}=\left[\begin{array}{l}
\delta_{\mathrm{rc}} \\
\delta_{\mathrm{ac}}
\end{array}\right] \begin{aligned}
& \text { rudder command }(\mathrm{rad}) \\
& \text { aileron command }(\mathrm{rad})
\end{aligned}
$$

The outputs are:

$$
\mathrm{y}=\left[\begin{array}{c}
\mathrm{r}_{\mathrm{a}} \\
\mathrm{p}_{\mathrm{a}} \\
\varphi \\
\mathrm{x}_{7}
\end{array}\right] \begin{gathered}
\text { roll acceleration }\left(\mathrm{rad} / \mathrm{s}^{2}\right) \\
\text { yaw acceleration }\left(\mathrm{rad} / \mathrm{s}^{2}\right) \\
\text { bank angle }(\mathrm{rad})
\end{gathered}
$$

In the notation of (1), the matrices $\mathrm{A}, \mathrm{B}$ and $\mathrm{C}$ can be obtained from (Tan and Edwards, 2001), whereas the matrices D and $\mathrm{E}$ are: 
Am. J. Applied Sci., 8 (10): 1032-1040, 2011

$\mathrm{D}=\left[\begin{array}{ccccccc}0 & 0 & 0 & 0 & 0 & 20 & 0 \\ 0 & 0 & 0 & 0 & 0 & 0 & 25\end{array}\right]^{\mathrm{T}}, \mathrm{E}=\left[\begin{array}{ccccccc}1 & 1 & 0 & 0 & 1 & 0 & 0\end{array}\right]^{\mathrm{T}}$

It can be easily verified that the Assumptions 3 and 4 are satisfied. Hence, the method proposed in this paper can be used. Performing the co-ordinate transformation $\mathrm{T}$ to obtain the canonical form described in (6)-(7) yields the following matrices:

$$
\begin{aligned}
& \mathrm{A}_{1}=\left[\begin{array}{cc}
\mathrm{A}_{11} & \mathrm{~A}_{12} \\
0 & \mathrm{~A}_{22}
\end{array}\right]=\left[\begin{array}{ccc}
-2.0722 & -3.6559 & -3.905 \\
0 & -0.3828 & 0.2493 \\
0 & -0.2039 & 0.1328
\end{array}\right] \\
& \mathrm{A}_{3}=\left[\begin{array}{ll}
0_{(\mathrm{p}-\mathrm{k}) \mathrm{xl}} & \mathrm{A}_{31} \\
\hline \mathrm{A}_{32}
\end{array}\right]=\left[\begin{array}{ccc}
0 & 0.7466 \\
20.0205 & 0.3060 & -7.6360 \\
14.8655 & -4.9725 & -7.6360 \\
-4.8825 & 1.4349 & 0.6572
\end{array}\right] \\
& \mathrm{D}_{2}=\left[\begin{array}{ccc}
0 & 0 \\
0 & 25.6651 \\
-16.1024 & 10.1712 \\
2.7488 & -4.7423
\end{array}\right], \mathrm{E}_{2}=\left[\begin{array}{cc}
0 \\
0 \\
1.4442
\end{array}\right] \\
& \mathrm{C}_{2}=\left[\begin{array}{cccc}
-0.0000 & -0.4099 & 0.9059 & -0.1066 \\
0.0000 & -0.9049 & -0.3891 & 0.1724 \\
-0.7071 & 0.0811 & 0.1182 & 0.6924 \\
0.7071 & 0.0811 & 0.1182 & 0.6924
\end{array}\right]
\end{aligned}
$$

It can be verified that the system (A, E, D, C) has an invariant zero at -2.0722 and the pair $\left(\mathrm{A}_{22}, \mathrm{~A}_{31}\right)$ is completely observable.

Observer design: Suppose that wish to assign the eigenvalues of the sliding mode represented by the system matrix $\mathcal{A}_{1}$ to lie in the intersection of the following regions:

- A circle of centre $(0,0)$ and radius 5

- A vertical upper bound at $\mathrm{x}=-2$

- A conic sector symmetric about the real axis, with inner angle $\theta=40$

When we refer to synthesis procedure and the imposing of the constraints (23) and (41)-(43), we deduce that the Matlab's LMI toolbox in (Gahinet et al., 1995) returns the values of $\mathrm{P}_{1}, \mathrm{P}_{2}$ and $\mathrm{L}$ :

$$
\begin{aligned}
P_{1} & =\left[\begin{array}{ccc}
2.7787 & 5.9150 & -0.7805 \\
5.9150 & 12.8312 & 0.3745 \\
-0.7805 & 0.3745 & 27.6181
\end{array}\right] \\
P_{2} & =\left[\begin{array}{llll}
1.8125 & 0.5929 & 0.2844 & -0.0840 \\
0.5929 & 0.1963 & -0.0274 & -0.1233 \\
0.2844 & -0.0274 & 14.3476 & -0.0877 \\
-0.0840 & -0.1233 & -0.0877 & 13.5485
\end{array}\right] \\
L_{1} & =\left[\begin{array}{llll}
-100.9428 \\
48.9719 \\
-7.0770
\end{array}\right]
\end{aligned}
$$

The poles of matrix $\mathcal{A}_{\mathrm{s}}$ are located at $-2.2,-2.4$, 2.6 and -2.8 , respectively. Consequently, the associated gain matrices from the observer representation in (8) are:

$$
\begin{array}{r}
G_{1}=10^{3} \times\left[\begin{array}{rrrr}
-0.0000 & -0.0000 & 0.0216 & -0.0190 \\
0.0010 & -0.0000 & 0.0724 & -0.0752 \\
0.0000 & 0.0010 & 0.0493 & -0.0531 \\
-0.0000 & 0.0000 & -0.0368 & 0.0392 \\
-0.0000 & -0.0000 & 0.0139 & -0.0146 \\
0.0236 & -0.0007 & 0.7566 & -0.7442 \\
0.0091 & 0.0199 & -1.2369 & 1.2223
\end{array}\right] \\
G_{\mathrm{n}}=\left[\begin{array}{ccccc}
0.0000 & 0.0000 & 1.0000 & 0.0000 \\
-0.0000 & -0.0000 & 27.8482 & -26.8482 \\
-0.0000 & -0.0000 & 18.9579 & -18.9579 \\
0.0000 & 0.0000 & -17.0234 & 17.0234 \\
-0.0000 & 0.0000 & -0.0000 & 1.0000 \\
-1.3269 & 0.0379 & -43.4828 & 43.2690 \\
-0.3993 & -0.8814 & 55.2180 & -55.0600
\end{array}\right]
\end{array}
$$

Robust state estimation: In the simulations that follow, the scalar function $\eta(y, u, t)$ from (10) was chosen to be 200 and $\sigma$ was chosen to be $10^{-5}$. Furthermore, the system was assumed to have an initial

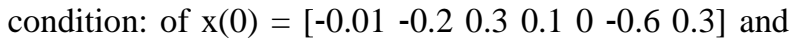
the observer was assumed to have zero initial condition. A disturbance $d=3 \sin (0.5 \mathrm{t})$ is applied to the system from $\mathrm{t}=0$. Both actuators were assumed to be faulty. The fault on the first actuator is a ramp signal applied at $\mathrm{t}=15 \mathrm{~s}$ and settles at $\mathrm{t}=20 \mathrm{~s}$ and the fault on the second actuator starts at $\mathrm{t}=10 \mathrm{~s}$, settles at $\mathrm{t}=15 \mathrm{~s}$ and switches at $\mathrm{t}=20 \mathrm{~s}$. Figure 1 show the trajectories of system states $\mathrm{x}$ as well as the estimates $\mathrm{x}$ provided by the scheme in this paper. It shows that the estimates converge very quickly to the actual states. 

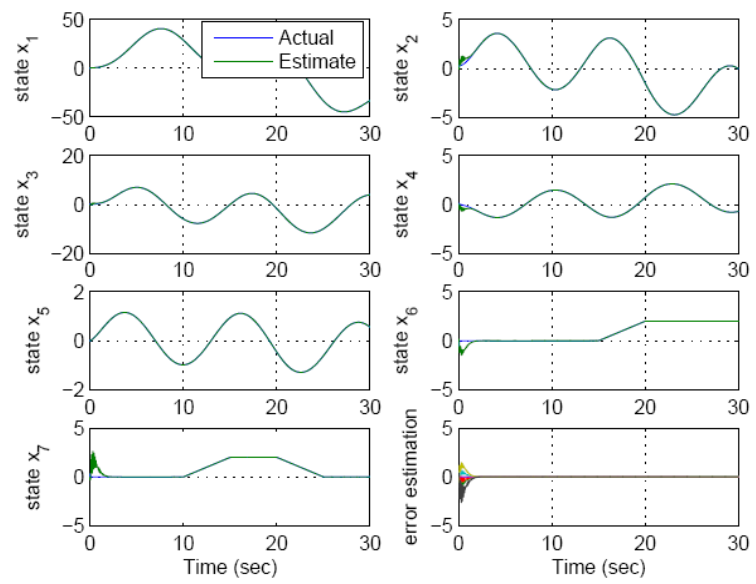

Fig. 1: The system states and the observers estimates
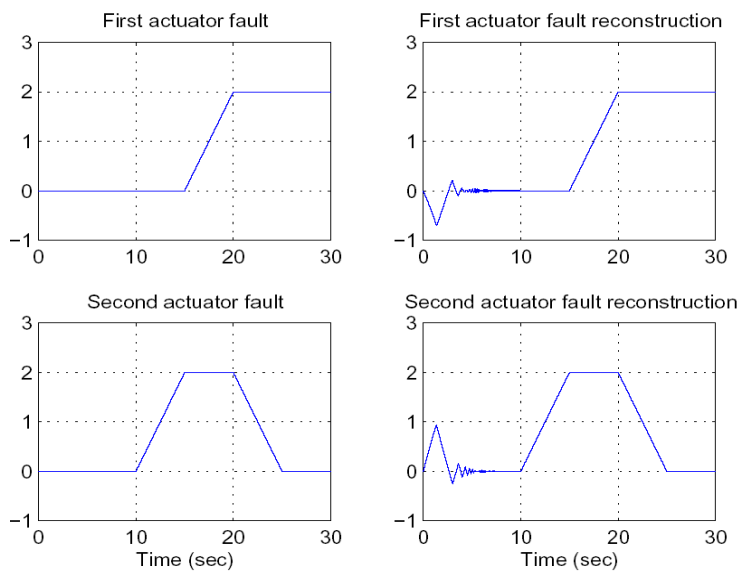

Fig. 2: Actuator fault and its reconstruction for the noise free simulation
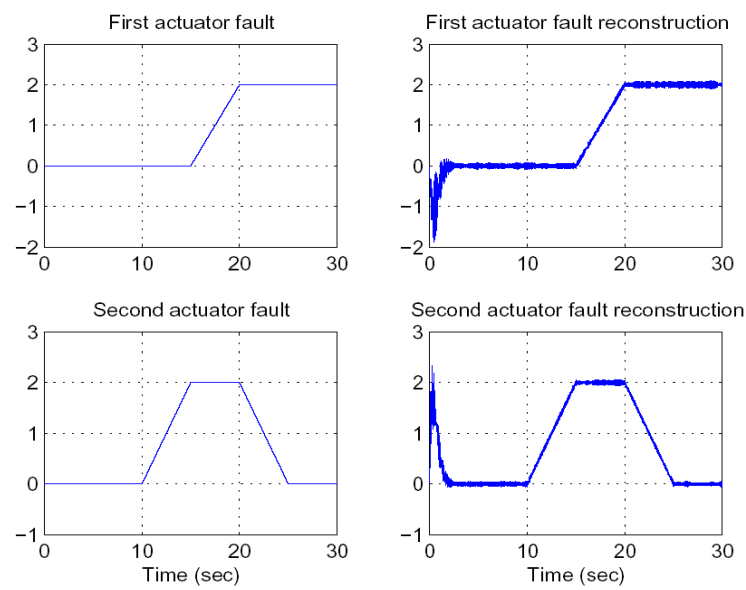

Fig. 3: Actuator fault and its reconstruction with noise
Robust actuator faults reconstruction: A suitable choice of the decoupling matrix is:

$$
\mathrm{W}=\left[\begin{array}{lll}
0 & 0 & 1 \\
0 & 1 & 0 \\
1 & 0 & 0
\end{array}\right] \text { and } \mathrm{H}_{2}=\left[\begin{array}{cc}
-16.1024 & 10.1712 \\
0 & 25.6651
\end{array}\right]
$$

Then, for any fault $f_{a}(t)$, the signal $\hat{f}_{a}(t)$ obtained from (52) is a reconstruction of the fault. Figure 2 shows the faults that are applied to the actuators as well as their reconstructions. It is clear that the sliding mode observer faithfully reconstructing faults simultaneously occurring in both actuators despite the effect of the uncertainty and initial condition of the system.

Figure 3 considers the case when the sensor signals were subject to white noise of standard deviation of 10-4. It shows satisfactory actuator fault reconstruction in the presence of noise.

\section{CONCLUSION}

This study has proposed a method for robust actuator and sensor faults reconstruction in uncertain linear systems using sliding mode observer. Compared to existing works, the observer in this study eliminates completely the effect of uncertainty on the state estimation and fault reconstruction. This method is initially formulated to solve the problem of actuator faults reconstruction. It is extended to the case of sensor faults by the introduction of an appropriate filter. The simulation for a real model of the seventh-order aircraft shows that the method provided by present paper has good performances.

\section{REFERENCES}

Chamsai, T., P. Jirawattana and T. Radpukdee, 2010. Sliding mode control with PID tuning technique: an application to a DC servo motor position tracking control. Energy Res. J., 1: 55-61. DOI: 10.3844/erjsp.2010.55.61

Chatchanayuenyong, T., 2009. A fast series active filter using sliding mode control to correct and regulate unbalance voltage in three-phase system. Am. J. Eng. Applied Sci., 2: 393-398. DOI: 10.3844/ajeassp.2009.393.398

Chen, J. and R. Patton, 1999. Robust Model-Based Fault Diagnosis for Dynamic Systems. 1st Edn., Kluwer Academic Publishers, Boston, Mass, ISBN: 0792384113, pp: 256. 
Chilali, M. and P. Gahinet, 1996. $\mathrm{H}_{\infty}$ design with pole placement constraints: An LMI approach. IEEE Trans. Automatic Control, 41: 358-367. DOI: 10.1109/9.486637

Edwards, C. and S.K. Spurgeon, 1998. Sliding Mode Control: Theory and Applications. 1st Edn., Taylor and Francis, London, ISBN: 0748406018, pp: 237

Edwards, C., S.K. Spurgeon and R.J. Patton, 2000. Sliding mode observers for fault detection and isolation. Automatica, 36: 541-553. DOI: 10.1016/S0005-1098(99)00177-6

Gahinet, P., A. Nemirovski, A.J. Laub and M. Chilali, 1995. LMI control toolbox. The MathWorks, Inc.

Gertler, J., 1998. Fault Detection and Diagnosis in Engineering Systems. 1st Edn., Marcel Dekker, New York, ISBN: 0824794273, pp: 484.

Patton, R. and P.M. Frank 2000. Issues of Fault Diagnosis for Dynamic Systems. 1st Edn., Springer, London, ISBN: 3540199683, pp: 597.

Prasannamoorthy, V. and N. Devarajan, 2011. Fault detection and classification in power electronic circuits using wavelet transform and neural network. J. Comput. Sci., 7: 95-100. DOI: 10.3844/jcssp.2011.95.100
Tan, C.P. and C. Edwards, 2001. An LMI approach for designing sliding mode observers. Int. J. Control, 74: 559-1568.

Tan, C.P. and C. Edwards, 2002. Sliding mode observers for detection and reconstruction of sensor faults. Automatica, 38: 1815-1821. DOI: 10.1016/S0005-1098(02)00098-5

Tan, C.P. and C. Edwards, 2003. Sliding mode observers for robust detection and reconstruction of actuator and sensor faults. Int. J. Robust Nonlinear Control, 13: 443-463. DOI: 10.1002/rnc.723

Utkin, V.I., 1992. Sliding Modes in Control and Optimization. 1st Edn., Springer-Verlag, Berlin, New York, ISBN: 3540535160, pp: 286.

Yan, X.G. and C. Edwards, 2007. Nonlinear robust fault reconstruction and estimation using a sliding mode observer. Automatica, 43: 605-1614. DOI: 10.1016/j.automatica.2007.02.008 